\title{
Study of Mushy-Zone Development in
} Dendritic Microstructures with Glass-Forming Eutectic
Matrices Using Electrostatic Levitation

\author{
Henry Kozachkov, ${ }^{1}$ Joanna A. Kolodziejska, ${ }^{1}$ Scott Roberts, ${ }^{1}$ John J. Z. Li, ${ }^{1}$ \\ William L. Johnson, ${ }^{1}$ and Douglas C. Hofmann ${ }^{1,2}$ \\ ${ }^{1}$ Keck Laboratory of Engineering, California Institute of Technology, 1200 East California Boulevard, Pasadena, CA 91125, USA \\ ${ }^{2}$ Engineering and Science Directorate, Jet Propulsion Laboratory, California Institute of Technology, 4800 Oak Grove Drive, \\ Pasadena, CA 91109, USA \\ Correspondence should be addressed to Douglas C. Hofmann; dch@caltech.edu
}

Received 23 April 2013; Accepted 19 May 2013

Academic Editors: L. Chang, Y. Sun, R. A. Varin, and H. Yoshihara

Copyright ( 2013 Henry Kozachkov et al. This is an open access article distributed under the Creative Commons Attribution License, which permits unrestricted use, distribution, and reproduction in any medium, provided the original work is properly cited.

The coarsening of dendrites in two bulk metallic glass matrix composites was investigated using noncontact techniques in a high vacuum electrostatic levitator. Progressive degrees of coarsening were observed after isothermal holds of varying duration. Specific volume and surface tension during heating and cooling were measured. Hysteresis in specific volume was observed.

\section{Introduction}

Bulk metallic glass matrix composites (BMGMCs) are a relatively new class of materials that have demonstrated benchmark material properties [1-3], such as extensive ductility in tension [4] and ultrahigh fracture toughness. These properties are obtained by reinforcing monolithic bulk metallic glasses (BMGs) with soft, crystalline dendrites, grown in situ from the liquid, that are effective at inhibiting crack growth. Amorphous metal hardwareboth monolithic and composite-has traditionally been fabricated by die-casting or suction-casting liquid into molds to form net-shapes. However, the length scale of the resulting composite microstructure is neither homogenous nor optimal for improving mechanical properties of the composite (Figure 1(b)). Recent work has explored the manufacture of net-shape composite parts using the technique of semisolid forging, with promising results [5]. However, successfully producing parts in this manner presents a series of difficult choices at each step in the process, due to the high sensitivity of these materials and techniques to processing conditions.
BMGs-the matrix material for BMGMCs-have been shown to be highly sensitive to processing conditions in general, with particular regard for levels of contamination and for thermal history. The most widely known commercial alloy, Vitreloy 1, has demonstrated widely divergent measurements of fracture toughness, which can be attributed to differing levels of dissolved oxygen, chemical purity, casting temperature, carbide impurities, and part thickness [6-9]. Recent work by Garrett et al. has demonstrated that changes in configurational enthalpy lead to a strong dependence of fracture toughness on thermal history for identically prepared alloys, even with no visible microstructural changes [10].

For BMGMCs, several studies have demonstrated a strong correlation between material properties and the morphology of the crystalline dendrites present in these alloys [11-13]. In particular, fracture toughness and ductility were found to depend on interplay between the length scales of the dendrites and that of the crack-tip plastic zone size in the amorphous matrix $[14,15]$. Specifically, toughening was observed when the dendrite length scale was found to be 


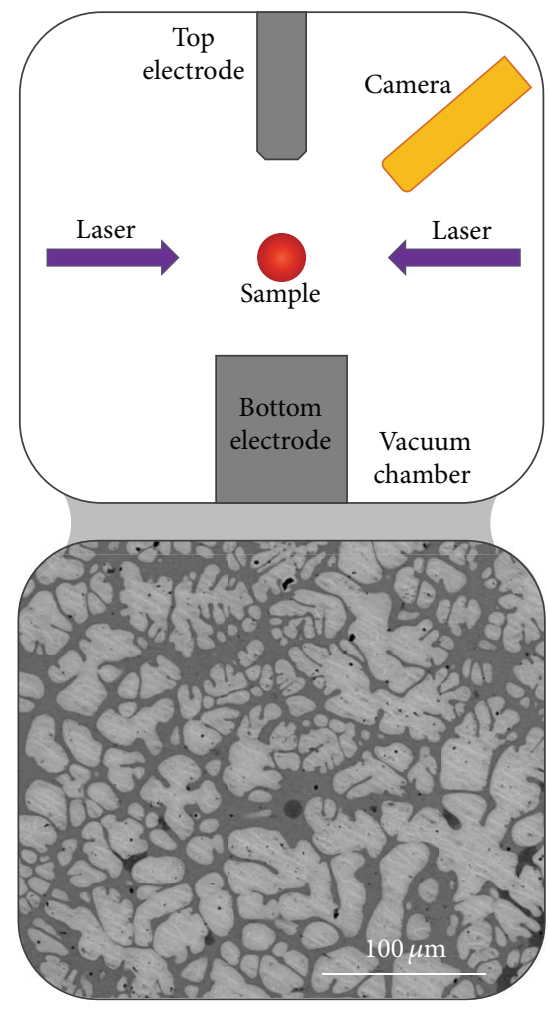

(a)

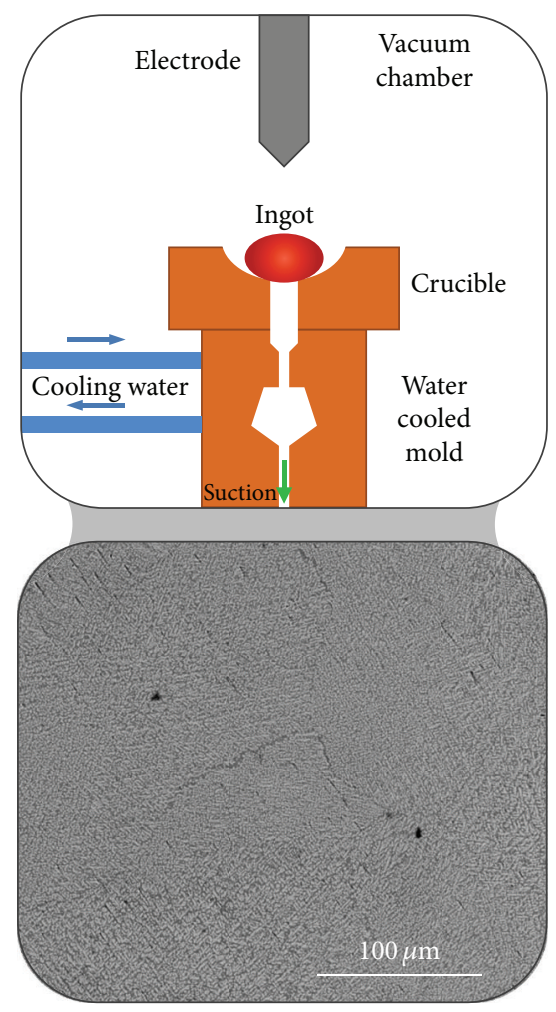

(b)

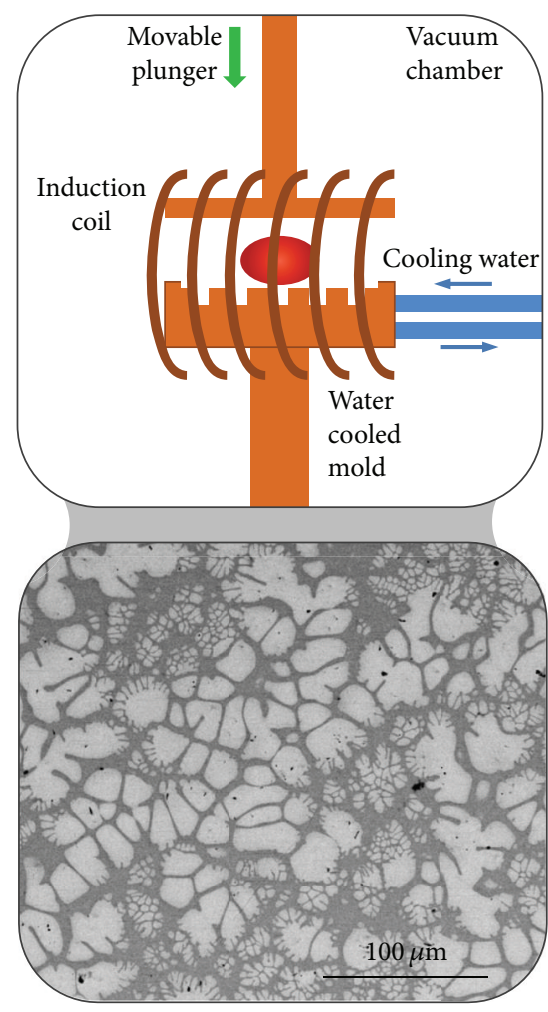

(c)

FIGURE 1: Schematic of a typical processing chamber configuration (a) ESL; (b) suction casting; (c) semisolid forging, with a corresponding SEM micrograph of BMGMC microstructure obtained from each method.

at least as large as the plastic zone size in the glass matrix, so that shear bands can be arrested by the dendrites before they elongate to a critical length and cavitate, initiating a crack. As detailed in [16], dendrite morphology can be altered independently of volume fraction by annealing in the semisolid regime. Volume fraction is controlled through alloy composition by varying the percentage of elements with little or no solubility in the b.c.c. dendrites and is relatively invariant to processing. Conversely, dendrite coarsening is a function of semisolid isothermal holding time and temperature. However, as the plastic zone size is itself dependent on the temperature history of the matrix [10], choosing a semisolid processing temperature profile presents a challenging multivariate optimization problem.

Because dendrite coarsening occurs between the solidus and liquidus temperatures, semisolid processing cannot be applied retroactively to shaped parts, such as those that have been cast from the liquid. Likewise, to retain the benefits of semisolid processing, the material cannot subsequently be reheated beyond the semisolid processing temperature for shaping. As detailed in [5], semisolid forging-by forging directly from the coarsened semisolid ingot-allows the production of net-shape BMGMC parts with optimized microstructure (Figure 1(c)). However, the interdependence of the processing and forming step introduces additional complexity; the manufacturability and surface finish of parts are strongly dependent on the viscosity of the ingot during forging, which varies very strongly with temperature.

The quality of manufactured BMGMC parts depends in a complex, convolved way on the processing history of the material, while the inextricability of individual parameters makes an iterative approach to process development prohibitively difficult. Thus, investigating these parameters accurately and in isolation becomes of critical importance. This is particularly true of the semisolid holding time/temperature (to control the dendrite microstructure) and the viscosity of the liquid (which is used in flow modeling to predict mold filling). Studying the effect of semisolid temperature and holding time is difficult using conventional techniques due to interactions with the crucible. In copper-cooled processes, such as induction heating or arc melting, for example, heating is highly nonisotropic due to the effects of conduction and radiation [5]. In induction heating, the effects of RF stirring further complicate the observed dendrite evolution. During oven heating, the highly reactive ingots wet the crucible material and become contaminated. Additionally, since viscosity is a strong function of temperature, any temperature inhomogeneities introduce large viscosity gradients in the sample. Thus, a sufficiently detailed investigation of semisolid processing parameters is enabled by a containerless technique 


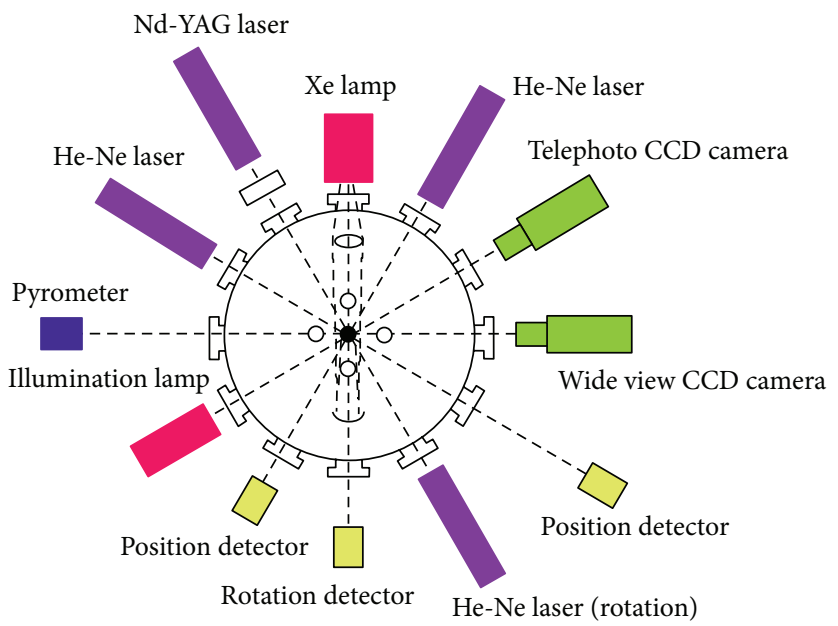

(a)

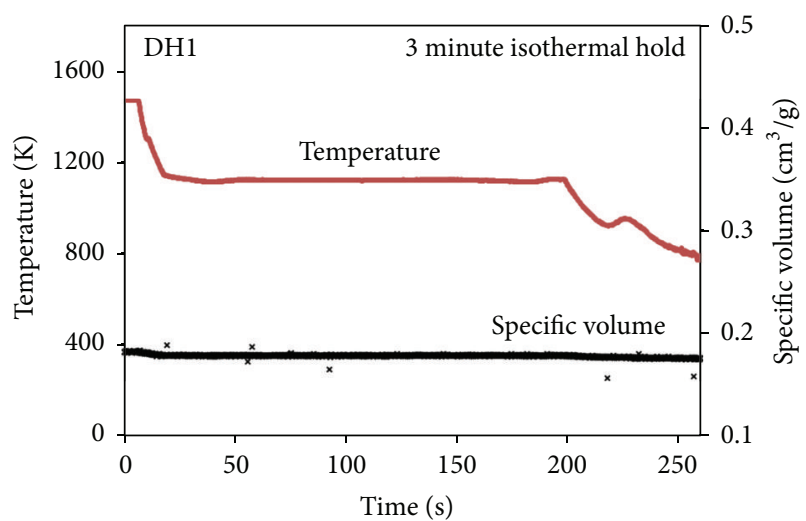

(b)

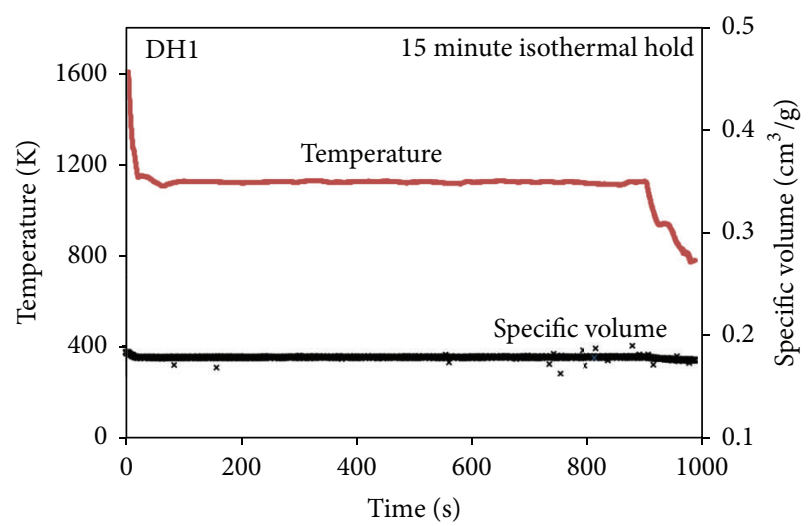

(c)

FIGURE 2: (a) Schematic configuration of the high vacuum electrostatic levitator; (b, c) plots of temperature versus time for DH1 during coarsening study, with hold times as indicated.

with high temperature isotropy. The electrostatic levitator (ESL) is uniquely suited to exploring this parameter space in a way not possible with other methods.

\section{Materials and Methods}

In this study, we use the electrostatic levitator (ESL) in lieu of furnace or induction heating, in an attempt to independently investigate dendrite coarsening and viscosity under containerless, near-isothermal conditions [17]. In the ESL, spherical samples are electrostatically levitated under high vacuum, while highly isotropic temperature control is achieved through the use of Nd-YAG lasers in a tetrahedral arrangement, with temperature measurement and feedback provided by a two-color pyrometer (Figure 2). Cooling is primarily radiative, with negligible conduction and convection. Specific volumes are calculated from captured CCD images, via Legendre polynomial fitting [18].

Samples of BMGMCs DH1 $\left(\mathrm{Zr}_{36.6} \mathrm{Ti}_{31.4} \mathrm{Nb}_{7} \mathrm{Cu}_{5.9} \mathrm{Be}_{19.1}\right)$ and DH3 $\left(\mathrm{Zr}_{39.6} \mathrm{Ti}_{33.9} \mathrm{Nb}_{7.6} \mathrm{Cu}_{6.4} \mathrm{Be}_{12.5}\right)$ were prepared from high purity $(>99.9 \%)$ elemental metals by arc melting on a water cooled copper hearth. Small $(\sim 30 \mathrm{mg})$ pieces of each composition were then prepared for use in the ESL. The BMGMCs DH1 and DH3 have been previously shown to have approximately $50 \%$ and $67 \%$ volume fraction of the crystalline dendrite phase, respectively. In both alloys, the glass matrix is similar in composition to $\mathrm{Zr}-\mathrm{Ti}-\mathrm{Be} \mathrm{BMGs}$ previously studied using the ESL technique [19-21]. For the investigation of dendrite development, each sample was subjected to one of three temperature profiles in the ESL: (1) heating to above liquidus $(\sim 1570 \mathrm{~K})$, followed by radiative cooling to below solidus, (2) heating to near liquidus, followed by radiative cooling to the lower end of the semisolid region $(\sim 1120 \mathrm{~K})$, followed by an isothermal hold of either (a) three or (b) fifteen minutes, followed by radiative cooling to below solidus (Figure 2). For the investigation of specific volume and hysteresis, a sample of each alloy was cycled between near liquidus $(\sim 1570 \mathrm{~K})$ and below solidus $(\sim 800 \mathrm{~K})$ for two complete cycles.

Samples were sectioned and polished in preparation for SEM. Resulting micrographs (Figure 3) were segmented into dendrite and matrix components via morphological opening and a Kittler-Illingsworth thresholding [22], followed by morphological segmentation. Numerical properties of 


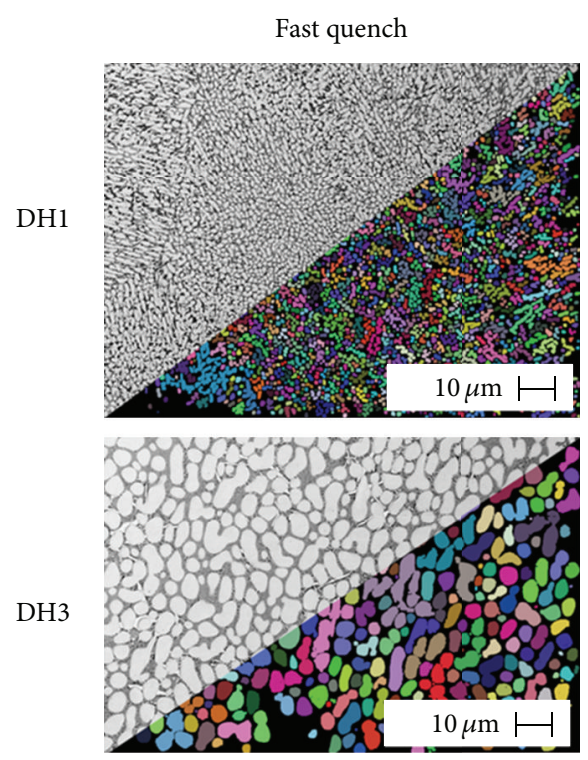

(a)

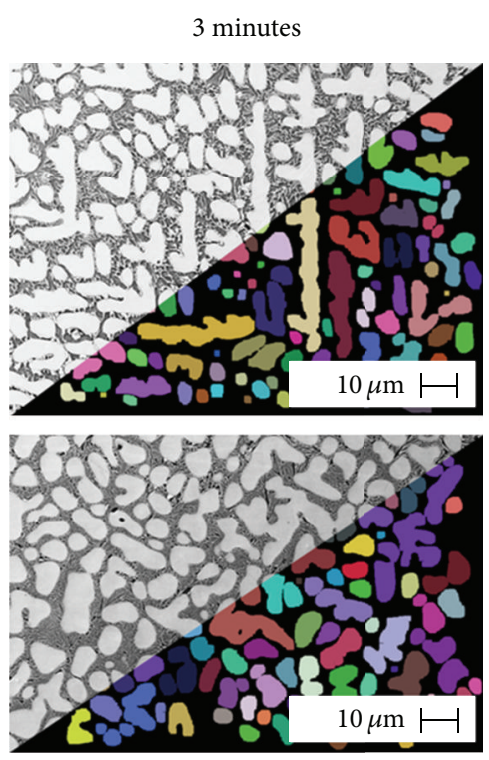

(b)

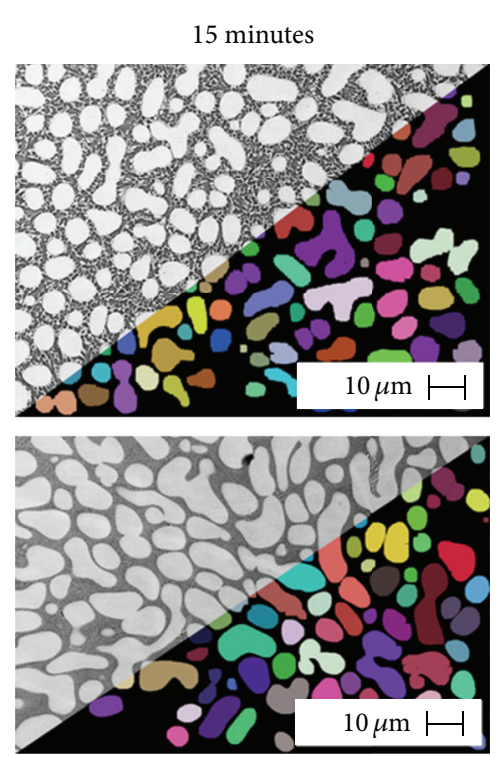

(c)

FIGURE 3: SEM micrographs of representative areas of processed samples from coarsening study, overlaid with processed and segmented version of each micrograph. Alloys and hold times as indicated. Note that the glass-forming matrix crystallized after ESL processing due to the inherently low cooling rates in the apparatus.

the dendrites were then calculated, including area fraction, dendrite specific perimeter, and mean area per dendrite. Dendrites bordering the edge of the micrograph were omitted from the latter two calculations. After segmentation, areas were calculated by pixel count, with each pixel weighted by its neighborhood configuration, while dendrite perimeters were calculated from the total length of outer pixel sides. Specific perimeter was defined as total dendrite perimeter over total dendrite area, as an indicator of dendrite coarsening.

Viscosity of the samples was measured in the ESL by the application of an oscillating excitation pulse from the lower electrode. This pulse causes the sample droplet to axisymmetrically oscillate, deviating from a spherical shape. These oscillations have a characteristic frequency, $\omega_{n}$, corresponding to the $n$th mode, given by

$$
\omega_{n}^{2}=n(n-1)(n+2) \frac{\sigma}{\rho r_{0}^{3}}
$$

where $\sigma$ is the surface tension, $\rho$ is the sample density, and $r_{0}$ is the spherical radius of the drop. For this study we investigated the second mode. The damping constant, $\tau$, is related to the sample viscosity, $\eta$, by

$$
\frac{1}{\tau_{2}}=\frac{5 \eta}{\rho r_{0}^{2}}
$$

The surface tension of the sample can be found from the angular oscillation frequency, $\omega_{2 c}$, and the drop charge, $Q_{s}$ as follows:

$$
\sigma=\frac{r_{0}^{3} \rho}{8}\left(\omega_{2 c}^{2}+\frac{Q_{s}^{2}}{8 \pi^{2} r_{0}^{6} \rho \varepsilon_{0}}\right)
$$

TABLE 1: Measured parameters for crystalline phase after isothermal holds.

\begin{tabular}{ccccc}
\hline Alloy & Hold time (s) & $\begin{array}{c}\text { Area } \\
\text { fraction }\end{array}$ & $\begin{array}{c}\text { Specific } \\
\text { perimeter } \\
\left(\mu \mathrm{m}^{-1}\right)\end{array}$ & $\begin{array}{c}\text { Mean area } \\
\text { per dendrite } \\
\left(\mu \mathrm{m}^{2}\right)\end{array}$ \\
\hline \multirow{3}{*}{ DH1 } & 0 & .45 & 2.2 & 5.1 \\
& 180 & .47 & .37 & 158 \\
& 900 & .47 & .33 & 191 \\
\hline \multirow{2}{*}{ DH3 } & 0 & - & .62 & 66 \\
& 180 & .57 & .33 & 228 \\
& 900 & .62 & .28 & 329 \\
\hline
\end{tabular}

where $\varepsilon_{0}$ is the vacuum permittivity and $Q_{s}$ is determined by the levitation condition. A more rigorous derivation is presented in [23].

\section{Results and Discussion}

Dendrite coarsening was observed for both DH1 and DH3 following isothermal holds at $1120 \mathrm{~K}$ using the ESL apparatus (Table 1). Tests on DH1 showed that average specific perimeter of the dendrites decreased with increasing isothermal hold times. Accordingly, mean area per dendrite rises significantly with increasing isothermal hold time, indicative of dendrite coarsening. DH3 exhibited dendrite coarsening behavior comparable to DH1 when subjected to the same thermal cycling procedure. All isothermal annealing was performed at $1120 \mathrm{~K}$, in the semisolid regime of the composite.

As expected, the area fraction of the dendrites remained roughly the same throughout all temperature cycles for both 


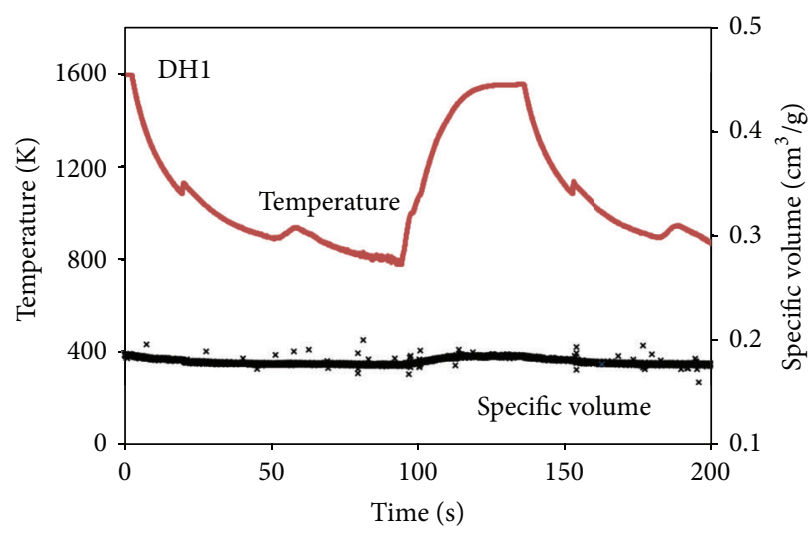

(a)

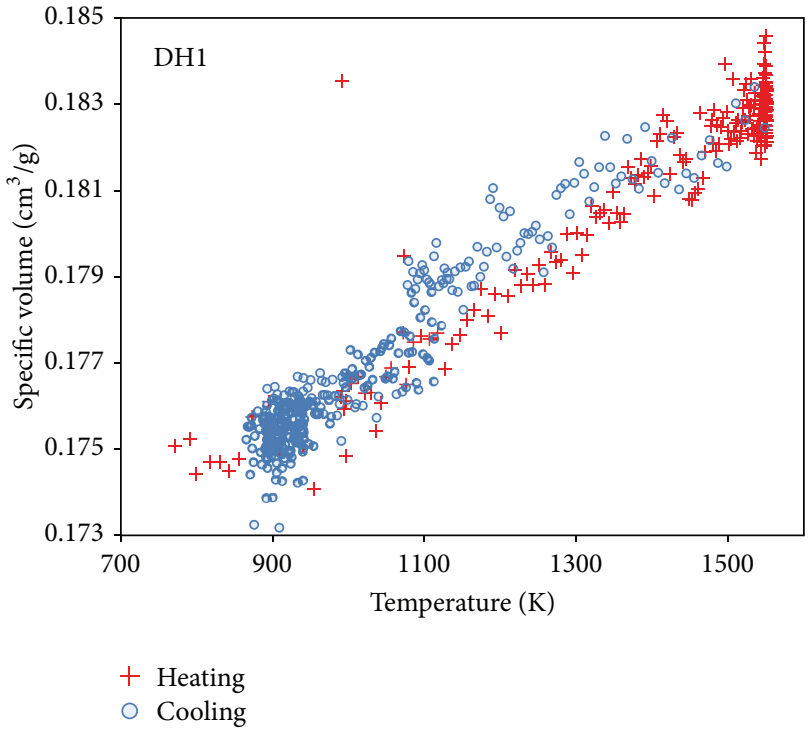

(c)

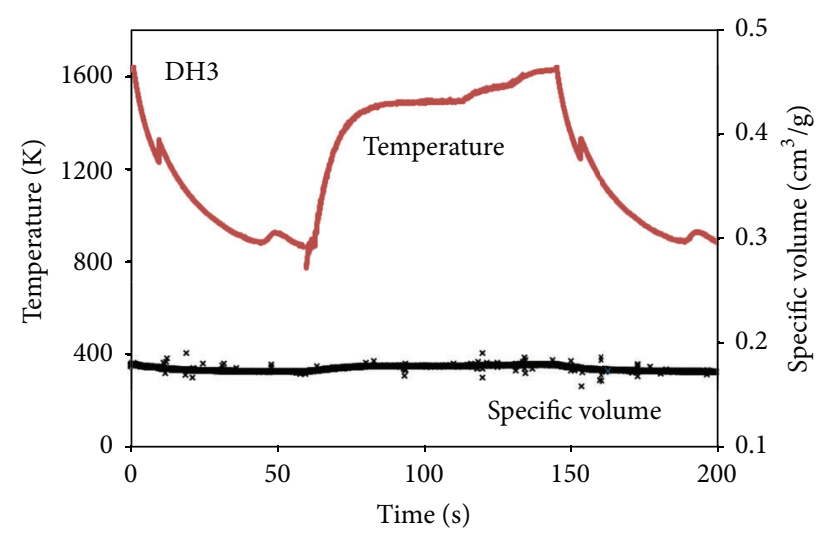

(b)

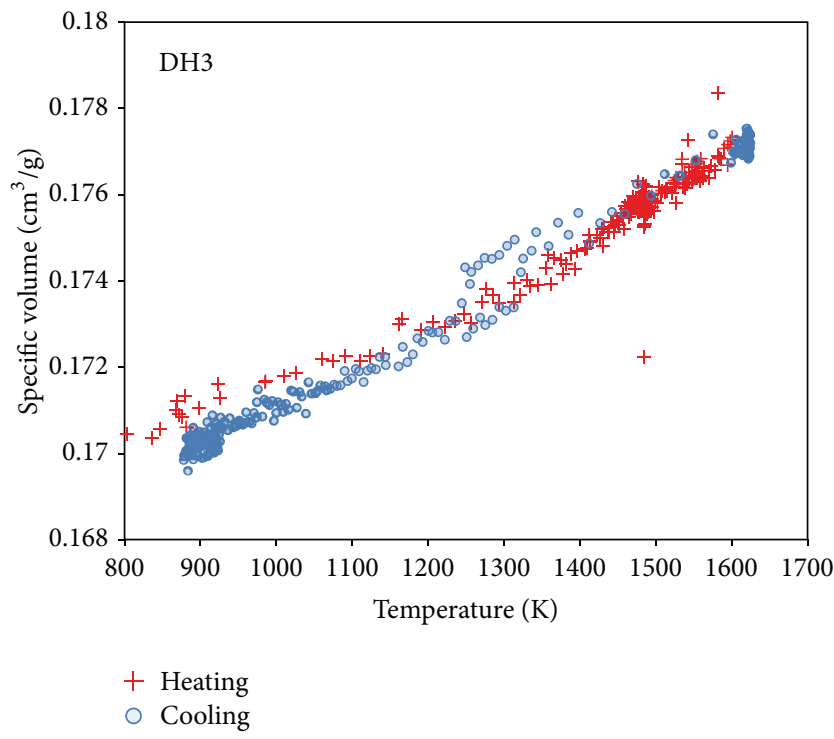

(d)

Figure 4: (a, b) Temperature and specific volume versus time for cooling and heating cycle from hysteresis study, for DH1 and DH3, respectively. (c), (d) Scatter plots of specific volume versus temperature for a heating and cooling cycle, showing hysteresis, for DH1 and $\mathrm{DH} 3$, respectively.

DH1 and DH3, with variation attributable to sampling. The data show that isothermal holds in the semisolid region of the metal matrix composites $\mathrm{DH} 1$ and $\mathrm{DH} 3$ resulted in coarsening of dendrites in the matrix. As the mean area per dendrite increased significantly, this appears to be an example of Ostwald Ripening, in which, for a given volume of inclusions, a system's tendency to minimize interfacial energy results in larger structures being favorable to smaller ones [24]. The measured decrease in specific perimeter corresponds to a decrease in interfacial area, as expected of this process.

In the hysteresis studies for both alloys, temperature versus time plots (Figure 4) revealed two distinct humps during the cooling phase. As the higher-temperature hump is accounted for by crystallization of the dendrites, the lower temperature hump may be indicative of the matrix crystallizing due to the limited cooling rate of the ESL apparatus. High temperature hysteresis in specific volume is particularly evident in $\mathrm{DH} 3$ but present in $\mathrm{DH} 1$ as well.

Viscosity was measured for both DH1 and DH3 samples over a range of temperatures in the semisolid range. Measurements were done in the undercooled liquid regime, as the precipitation of dendrites increased the viscosity beyond the range of the equipment. For DH1, viscosity measurements were obtained for temperatures between $1089 \mathrm{~K}$ and $1397 \mathrm{~K}$. For DH3, measurements were taken between $1218 \mathrm{~K}$ and $1615 \mathrm{~K}$. For both alloys, the viscosity is observed to decrease with increasing temperature, which is typical of vitreous alloy systems (Figure 5). Surface tension measurements were performed over the same temperatures ranges for each alloy, again in the undercooled liquid regime. The surface tension of DH3 clearly increases with temperature; this trend is markedly different from most other alloy systems but not unprecedented in systems with deep eutectics [25]. 


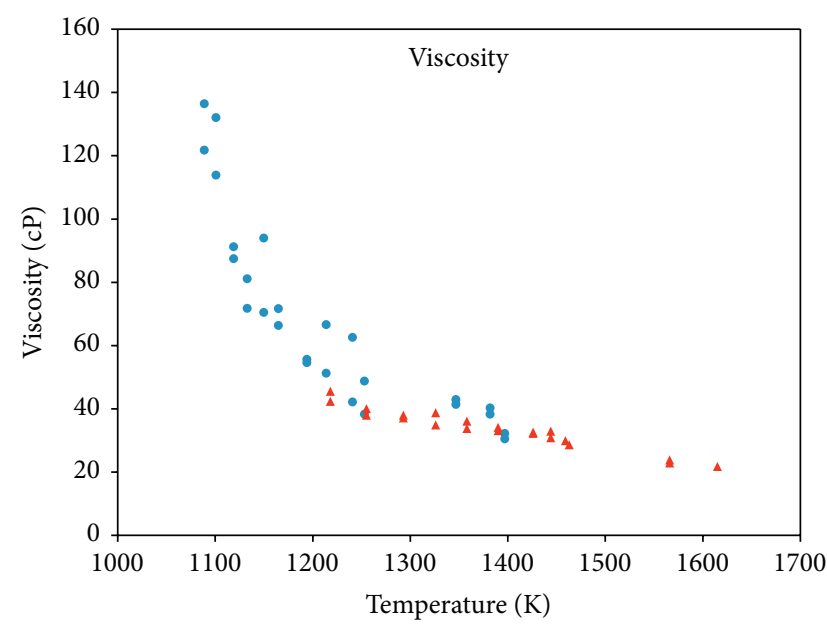

- DH1

$\Delta \mathrm{DH} 3$

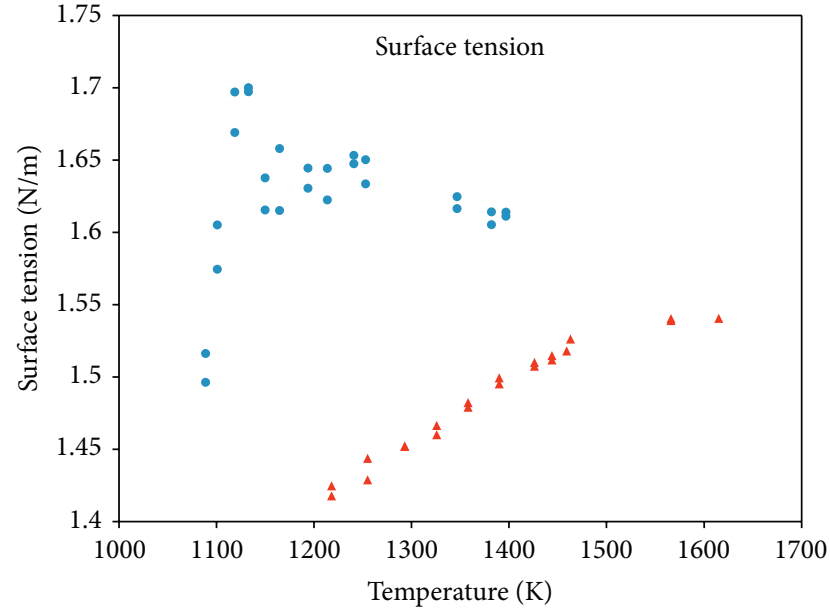

- $\mathrm{DH} 1$

$\triangle \mathrm{DH} 3$

(a)

(b)

FIGURE 5: Viscosity and surface tension measurements for DH1 and DH3 performed in the ESL.

\section{Conclusions}

This work demonstrates that semisolid processing and rheological investigation of BMGMCs are achievable in the containerless, highly isothermal conditions provided by the ESL. This represents the first published measurements of viscosity for BMGMCs. In concordance with previous works, annealing samples in the semisolid region led to quantifiable Oswald ripening on the crystalline dendrites. Going forward, an accurate understanding of the interplay between annealing temperature and duration and the resulting microstructure of BMGMCs is of paramount importance for their use as engineering materials. The detailed control of the environmental factors in the ESL as well as the noncontact nature of the processing and measurement will allow future works to probe these issues in ways not previously possible. Ongoing work with the ESL and other instruments exploring rheology in both the liquid and semisolid regions will provide further data useful in the development of processing techniques and mold designs optimized for these materials. Furthermore, the ESL presents the processing conditions closest to the microgravity environment on the International Space Station's Materials Science Lab (MSL). As such, use of the ESL may pave the way for further such investigations using the MSL, elucidating any subtle effects masked by terrestrial gravity. Taken together, the detailed investigations made possible by these tools will be invaluable in the continuing commercialization of these materials and the manufacturing techniques applicable to them.

\section{Acknowledgments}

This work was supported by NASA's Exploration Systems Mission Directorate under Contract no. NNH10ZTT001N. Part of this work was completed at the Jet Propulsion Laboratory, California Institute of Technology.

\section{References}

[1] D. C. Hofmann, J. Suh, A. Wiest et al., "Designing metallic glass matrix composites with high toughness and tensile ductility," Nature, vol. 451, no. 7182, pp. 1085-1089, 2008.

[2] D. C. Hofmann, J. Suh, A. Wiest, M. Lind, M. D. Demetriou, and W. L. Johnson, "Development of tough, low-density titaniumbased bulk metallic glass matrix composites with tensile ductility," Proceedings of the National Academy of Sciences of the United States of America, vol. 105, no. 51, pp. 20136-20140, 2008.

[3] J. P. Schramm, D. C. Hofmann, M. D. Demetriou, and W. L. Johnson, "Metallic-glass-matrix composite structures with benchmark mechanical performance," Applied Physics Letters, vol. 97, Article ID 241910, 2010.

[4] D. C. Hofmann, J. Suh, A. Wiest, and W. Johnson, "New processing possibilities for highly toughened metallic glass matrix composites with tensile ductility," Scripta Materialia, vol. 59, no. 7, pp. 684-687, 2008.

[5] D. C. Hofmann, H. Kozachkov, H. E. Khalifa et al., "Semi-solid induction forging of metallic glass matrix composites," JOM, vol. 61, no. 12, pp. 11-17, 2009.

[6] M. E. Launey, D. C. Hofmann, J.-Y. Suh, H. Kozachkov, W. L. Johnson, and R. O. Ritchie, "Fracture toughness and crackresistance curve behavior in metallic glass-matrix composites," Applied Physics Letters, vol. 94, no. 24, Article ID 241910, 2009.

[7] P. Lowhaphandu and J. J. Lewandowski, "Fracture toughness and notched toughness of bulk amorphous alloy: $\mathrm{Zr}-\mathrm{Ti}-\mathrm{Ni}-\mathrm{Cu}-$ Be," Scripta Materialia, vol. 38, no. 12, pp. 1811-1817, 1998.

[8] K. M. Flores and R. H. Dauskardt, "Enhanced toughness due to stable crack tip damage zones in bulk metallic glass," Scripta Materialia, vol. 41, pp. 937-943, 1999.

[9] C. J. Gilbert, V. Schroeder, and R. O. Ritchie, "Mechanisms for fracture and fatigue-crack propagation in a bulk metallic glass," Metallurgical and Materials Transactions A, vol. 30, no. 7, pp. 1739-1753, 1999. 
[10] G. R. Garrett, M. D. Demetriou, J. Chen, and W. L. Johnson, "Effect of microalloying on the toughness of metallic glasses," Applied Physics Letters, vol. 101, Article ID 241913, 2012.

[11] J. W. Qiao, S. Wang, Y. Zhang, P. K. Liaw, and G. L. Chen, "Large plasticity and tensile necking of Zr-based bulk-metallic-glassmatrix composites synthesized by the Bridgman solidification," Applied Physics Letters, vol. 94, Article ID 151905, 2009.

[12] J. M. Park, J. Jayaraj, D. H. Kim, N. Mattern, G. Wang, and J. Eckert, "Tailoring of in situ Ti-based bulk glassy matrix composites with high mechanical performance," Intermetallics, vol. 18, no. 10, pp. 1908-1911, 2010.

[13] M. L. Lee, Y. Li, and C. A. Schuh, "Effect of a controlled volume fraction of dendritic phases on tensile and compressive ductility in La-based metallic glass matrix composites," Acta Materialia, vol. 52, no. 14, pp. 4121-4131, 2004.

[14] C. C. Hays, C. P. Kim, and W. L. Johnson, "Microstructure controlled shear band pattern formation and enhanced plasticity of bulk metallic glasses containing in situ formed ductile phase dendrite dispersions," Physical Review Letters, vol. 84, p. 2901, 2000.

[15] J. Eckert, J. Das, S. Pauly, and C. Duhamel, "Mechanical properties of bulk metallic glasses and composites," Journal of Materials Research, vol. 22, no. 2, pp. 285-301, 2007.

[16] S. Y. Lee, C. P. Kim, J. D. Almer, U. Lienert, E. Ustundag, and W. L. Johnson, "Pseudo-binary phase diagram for Zr-based in situ $\beta$ phase composites," Journal of Materials Research, vol. 22, no. 2, pp. 538-543, 2007.

[17] J. Schroers, S. Bossuyt, W. Rhim, J. Li, Z. Zhou, and W. L. Johnson, "Enhanced temperature uniformity by tetrahedral laser heating," Review of Scientific Instruments, vol. 75, no. 11, pp. 4523-4527, 2004.

[18] S. Mukherjee, J. Schroers, Z. Zhou, W. L. Johnson, and W.-. Rhim, "Viscosity and specific volume of bulk metallic glassforming alloys and their correlation with glass forming ability," Acta Materialia, vol. 52, no. 12, pp. 3689-3695, 2004.

[19] Y. J. Kim, R. Busch, W. L. Johnson, A. J. Rulison, and W. $\mathrm{K}$. Rhim, "Metallic glass formation in highly undercooled $\mathrm{Zr}_{41.2} \mathrm{Ti}_{13.8} \mathrm{Cu}_{12.5} \mathrm{Ni}_{10.0} \mathrm{Be}_{22.5}$ during containerless electrostatic levitation processing," Applied Physics Letters, vol. 65, no. 17, pp. 2136-2138, 1994.

[20] S. Mukherjee, W. L. Johnson, and W. K. Rhim, "Noncontact measurement of high-temperature surface tension and viscosity of bulk metallic glass-forming alloys using the drop oscillation technique," Applied Physics Letters, vol. 86, no. 1, Article ID 014104, 2005.

[21] S. Mukherjee, H.-G. Kang, W. L. Johnson, and W.-K. Rhim, "Noncontact measurement of crystallization behavior, specific volume, and viscosity of bulk glass-forming $\mathrm{Zr}-\mathrm{Al}-\mathrm{Co}-(\mathrm{Cu})$ alloys," Physical Review B, vol. 70, no. 17, Article ID 174205, pp. $1-6,2004$.

[22] J. Kittler and J. Illingworth, "Minimum error thresholding," Pattern Recognition, vol. 19, no. 1, pp. 41-47, 1986.

[23] W. K. Rhim, K. Ohsaka, and P. F. Paradis, "Noncontact technique for measuring surface tension and viscosity of molten materials using high temperature electrostatic levitation," Review of Scientific Instruments, vol. 70, p. 2796, 1999.

[24] P. W. Voorhees, "The theory of Ostwald ripening," Journal of Statistical Physics, vol. 38, no. 1-2, pp. 231-252, 1985.

[25] I. Egry, G. Lohöfer, E. Gorges, and G. Jacobs, "Structure and properties of undercooled liquid metals," Journal of Physics Condensed Matter, vol. 8, no. 47, pp. 9363-9368, 1996. 

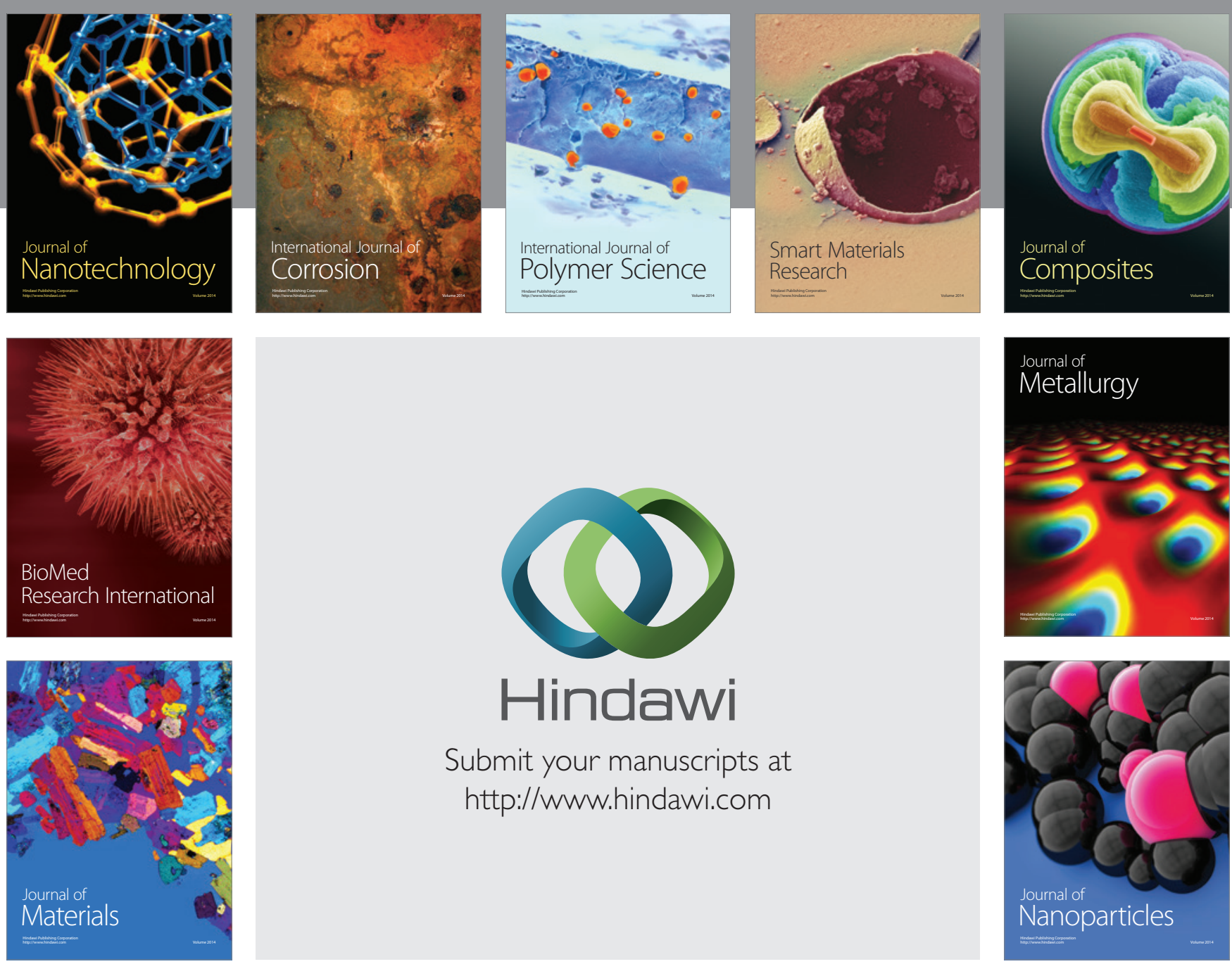

Submit your manuscripts at http://www.hindawi.com
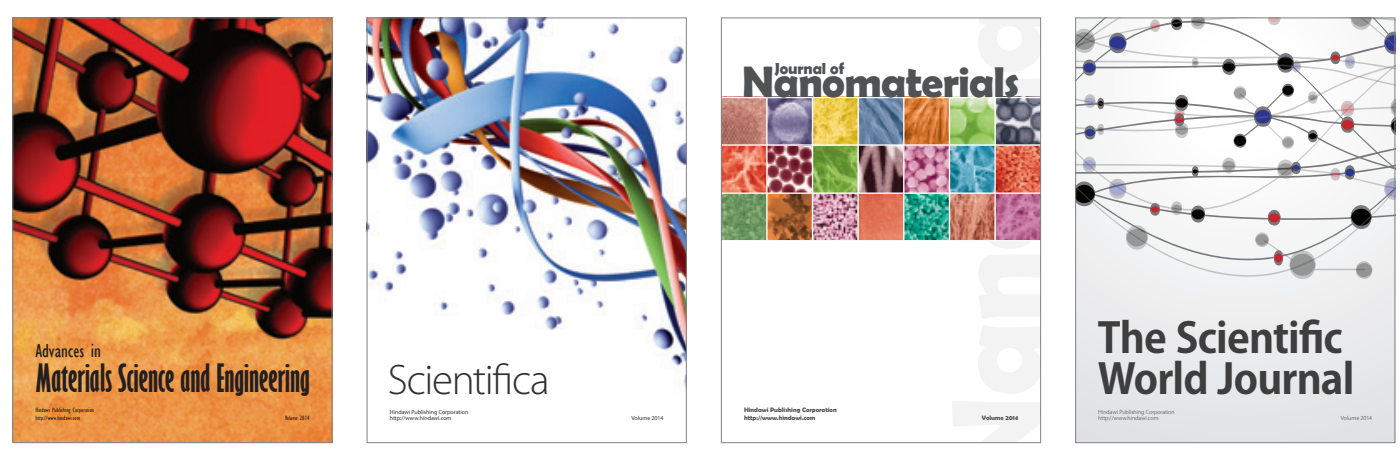

\section{The Scientific World Journal}
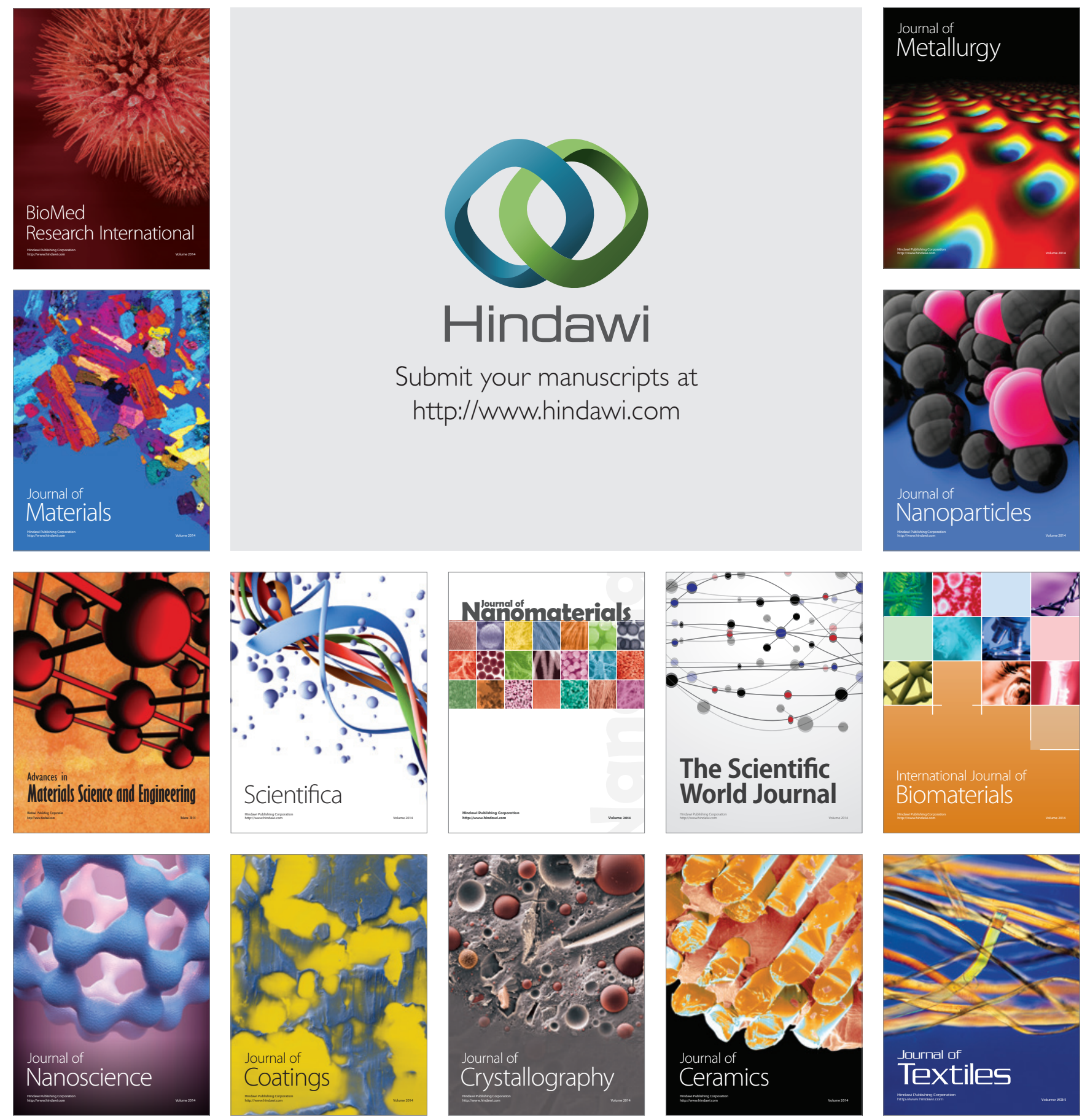